\title{
Research on Effects of Water Ratio of Emulsified Diesel on the
}

\section{Combustion Progress of Diesel Engine}

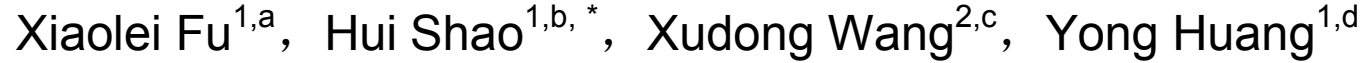 \\ ${ }^{1}$ Environment\&Safety Engineering College,Changzhou University, Changzhou, Jiangsu \\ China,213100; \\ ${ }^{2}$ Beijing POL Research Institute, Beijing,China,102300 \\ aa55806106aa@163.com, bhshao@cczu.deu.cn, 'wangxudong3637@163.com, \\ dhuangyong001@cczu.deu.cn
}

Keywords:Water Content; Cylinder Pressure; Heat Release Rate; Fuel Consumption Abstract.Using three-dimensional simulation software AVL FIRE establish a direct injection diesel model.Analyzes the effects of water content of emulsified diesel on the combustion progress of diesel engine.The results showed that with the diesel water content increasing, the maximum cylinder pressure generally declining until can not ignite. When water content is $3 \%$, the maximum cylinder pressure increased slightly about $0.15 \%$. Heat release rate curve further up the TDC and increase cycle work while reducing the compression work so that the combustion process can completed in advance; fuel consumption rate keep rising as the water porperty rising.However, after deducting the corresponding proportion of water, fuel consumption rate showed shrinking tendency, and fuel consumption to a minimum rate of $25 \%$ under aqueous conditions, fuel consumption rate reduce by $6.06 \%$ compared with the fuel not mixed with water.

\section{Introduction}

With the development of chinese economy, the car parca and car sales volume increase rapidly, and the resources shortage and environmental pollution are becoming more and more serious.The increasingly stringent emission regulations and rising oil prices make the clean fuel research becoming a hot topic. Emulsified diesel is a water-in-oil type emulsion fuel mixed system which consisits of oil, water and a certain amount of additives in a certain proportion, can be directly burning in modified engine. The emulsified diesel has good combustion property, low energy consumption, less pollution and other advantages compare with ordinary diesel ${ }^{[1]}$. Its water blending combustion $^{[2]}$,oil-saving mechanism and on the improvement of the diesel engine combustion process and emission characteristics ${ }^{[3]}$ has been proved.

In order to study the effect of emulsified diesel to engine power, economy and emission performance, Domestic and foreign scholars have done lots of experiments: By using self-developed RL type emulsifier, the water content of 5\% was successfully prepared by Han Da-ming ${ }^{[4]}$, The engine test shows that emulsified diesel shows same power performance compare with ordinary diesel while emulsified diesel could decrease fuel consumption and FSN. Sun-ping ${ }^{[5]}$ found that the emulsified diesel can be used in the diesel engine normally and achieve the dynamic performance, the combustion temperature and pressure in the small load area is lower than ordinary diesel; GongJing Song.etc ${ }^{[6]}$ found that the maximum combustion pressure in the high load region is higher than ordinary diesel when using emusifed diesel; With the increase of the concentration of light component, the ignition delay time of the emulsified fuel is shortened, and when light 
component is $10 \% \sim 20 \%$, the ignitiom delay time changes obviously, the ignition delay time is relatively small when light component content is high.Yasufumi Yoshimoto, Toshinori Kuramoto.etc $^{[7]}$ carried out experiment on marine diesel using emulsified diesel,study the influence of water content and inlet temperature on diesel engine combustion stability.

With the development and wide application of modern calculation methods of computer, numerical simulation technology can analyze the distribution of the various parameters in the cylinder with time and space, not only can reproduce the surface characteristics of cylinder working process, but also can reflect the microscopic mechanism, can greatly save the time and test cost, provides effective and accurate tools for studying the combustion process in the cylinder of diesel engine.

Using three-dimensional simulation software AVL FIRE establish a direct injection diesel model in this paper,and verify the validity of the model by experiment. Change the water ratio of emulsified diesel under conditions of calibration condition $(0 \%, 3 \%, 5 \%, 10 \%, 15 \%, 20 \%$, $25 \%, 30 \%, 40 \%$ and $45 \%$ ) and analyzes the effect of water ratio on combustion proccess.

\section{Computional Model}

Table 1 shows the main parameters of diesel engine and its injection system.Fig. 1 shows three dimensional engine model at TDC.The process of the numerical simulation of the engine cylinder is the process of solving the Navies-Stokes equation of compressible viscous fluid ${ }^{[8]}$.The energy conservation equation, momentum conservation equation, mass conservation equation, and the ideal gas state equation are suitable for whole process ${ }^{[9]}$. K-zeta-f turbulence model,Wave breakup model, Multi-component evaporate model, Walljet1 collision model,Schmidt particle interaction model are used in the calculation. Without considering the gas flow change in the intake port, the formation of NOx selecting Extended Zeldovich model, the formation of soot selecting the Kinetic model

Tab 1 Parameters of Diesel engine and Injection system

\begin{tabular}{cc}
\hline Parameters & Index \\
\hline Diameter $/ \mathrm{mm}$ & 150 \\
Stroke $/ \mathrm{mm}$ & 183 \\
Length of connecting rod $/ \mathrm{mm}$ & 320 \\
Compression ratio & $13-14$ \\
Plunger diameter $/ \mathrm{mm}$ & 13 \\
Nozzle diameter $/ \mathrm{mm}$ & 0.35 \\
Advance angle of fuel supply $/\left(^{\circ}\right) 1$ & 28 \\
Opening pressure $/ \mathrm{MPa}$ & 20.6 \\
Spray-cone angle $/\left({ }^{\circ}\right)$ & 140 \\
\hline
\end{tabular}

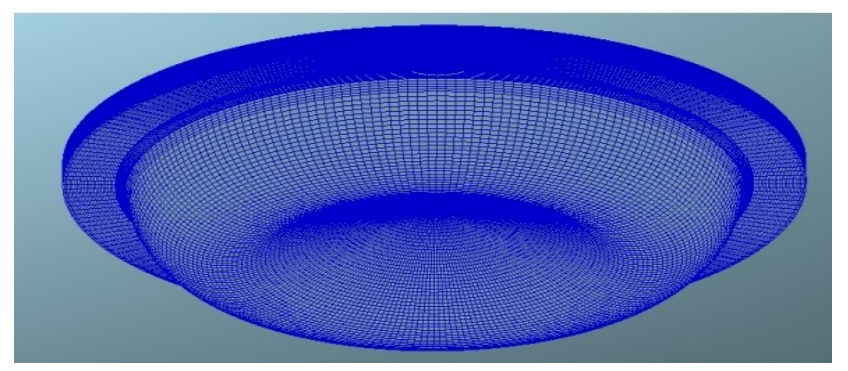

Fig. 1 Three Dimensional Engine Model at TDC 
After the model is established,the engine combustion chamber and the cylinder part are divided into the action grid. To $360 \mathrm{CA}$ for the intake stroke, the dynamic grid simulation process starts with the valve closing time (up to $130 \mathrm{CA}$ ) and terminates at the exhaust valve closing time (130 CA).

According to the flow field inside the engine, the boundary conditions can be simplified into three regions, the cylinder wall temperature is $410 \mathrm{~K}$ as wall surface; and the top surface of the piston wall temperature is $583 \mathrm{~K}$ as moving surface; the bottom of the cylinder surface temperature is $554 \mathrm{~K}$.

The diesel engine maximum torque when the moisture content is $0 \%$ of the diesel engine cylinder pressure was simulated and the results were compared with the actual test.Comparison of the calculated value between the test value is shown in Fig. 2.

By Fig. 2, it can be seen that the simulation results are close to the experimental results, the maximum data deviations is less than $8.3 \%$, the average data deviations is $4.39 \%$, the accuracy of the model meets the requirements, and accurate.

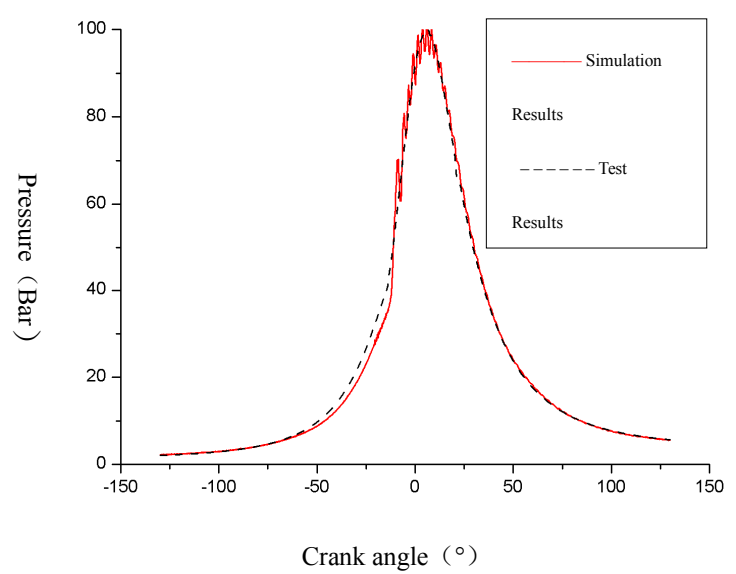

Fig. 2 Cylinder Pressure Simulation Value and Experiment Comparison

\section{Calculation result analysis}

Because of the large number of simulation results, the typical curves of the part of the calculation results are analyzed.

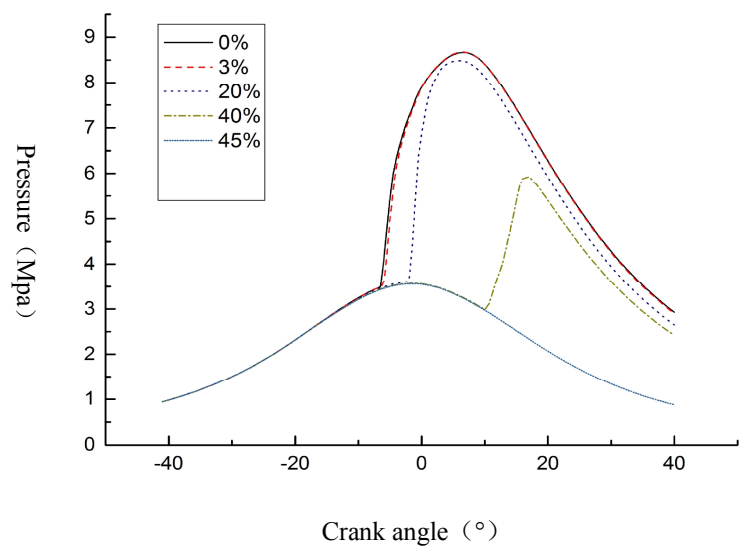

Fig. 3 Cylinder Pressure Comparison of Different Water Content

Pressure curve can reflect the combustion state and working efficiency of the diesel engine.Fig. 3 compares the pressure of emulsified diesel oil with different water content in cylinder. With the increase of the proportion of diesel mixed with water, the maximum combustion pressure decreases 
gradually. Water content of $5 \%, 15 \%, 20 \%, 25 \%, 30 \%, 35 \%, 40 \%, 3 \%$ and $45 \%$, respectively, the highest pressure in the cylinder was reduced by $0.018 \mathrm{Mpa}, 0.041 \mathrm{Mpa}, 0.089 \mathrm{Mpa}, 0.182 \mathrm{Mpa}$, $0.267 \mathrm{Mpa}, 0.606 \mathrm{Mpa}, 0.021 \mathrm{Mpa}, 2.730 \mathrm{Mpa}, 5.101 \mathrm{Mpa}$, and $8.665 \mathrm{Mpa}$, and the maximum pressure of the cylinder was increased by $0.15 \%$.

When the diesel mixed with a certain amount of water but the pressure inside the cylinder is not decrease when the endothermic effect of water drop makes the in cylinder temperature decreased,although in the combustion process cylinder temperature was decline, but the evaporation of water would cause the gas inside the cylinder volume expansion so that the cylinder pressure keep increasing, along with the continuous improvement of water ratio, the fuel volume of the diesel engine in the combustion chamber is kept constant in each working cycle,,but the quality of the diesel is less and less after the water be deducted so that the cylinder pressure decreased gradually untill unable to effectively burn and work.Fig. 3 shows that the emulsified diesel can not be ignited when water ratio reach to $45 \%$.

Fig. 4 compares the temperature of emulsified diesel oil with different water content in cylinder, as can be seen, when the water content increases, the maximum temperature and the average temperature in the cylinder will be decreased, the sensible heat and latent heat of water can be increased with the increase of water content. When the water content is too high, it will decrease the temperature of the cylinder, which would have a negative effect on the combustion process.

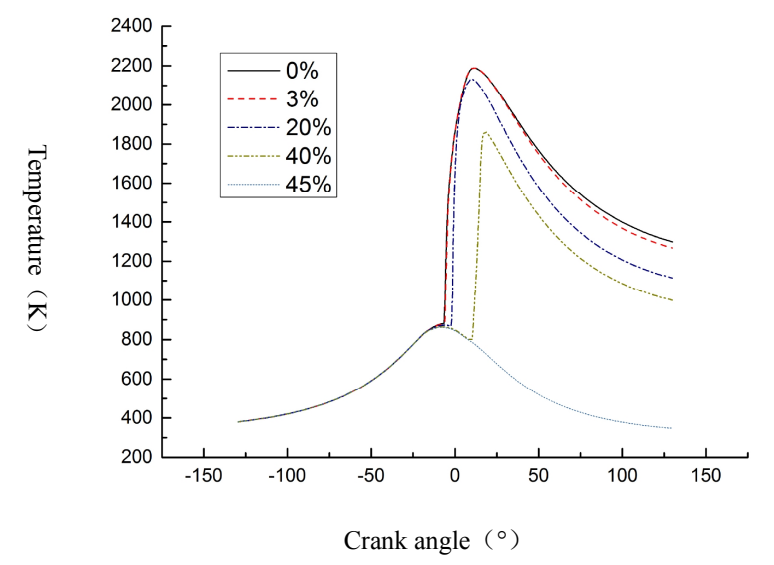

Fig .4 Cylinder Temperatue Comparison of Different Water Content

The heat release rate curve can characterize the degree of burn and speed of fuel, fig. 5 is the comparison of emulsified diesel exothermic rate of different moisture content.As it can be seen from the diesel exothermic curve, the duration of the heat release process is longer and exothermic process is slower,from which would lead to the combustible part of the existence of diesel with no oxidation exothermic reaction in the combustion process may exhaust cylinder thus affecting the thermal efficiency of the cylinder, In addition, due to the high cetane value of pure diesel, easy to catch fire. The combustion process can reach the point of stopping point and release some energy, so that the negative power of the compressor will be increased, so as to the cycle work.

When the diesel was doped with different amounts of water, as is shown in Fig. 5, the ignition delay time keeping increasing, the heat release rate curve will further reduce near TDC so that reduce the compression power. At the same time, the water is easier to evaporate than diesel.Before TDC, the rapid expansion of the vaporization occurred "micro explosion" phenomenon in the combustion chamber under high temperature, water is always the first to reach the boiling point and evaporation occured,making volume increased by 1500 times in a very short period of time.The small droplet vaporization expansion process is equivalent to a small explosion. When the pressure inside the oil droplets is greater than the pressure and the drop surface tension, the water vapor 
generated by the great pressure can break through the oil film's resistance making the oil droplets explode into smaller droplets, which can improve the oil droplets specific surface area, increase the reaction activity and thermal efficiency,so that the gas mixture process becomes more uniform, the most intuitive performance is shown after TDC, the heat release rapidly and continuously, increasing cycle work and making combustion process finished in advance.

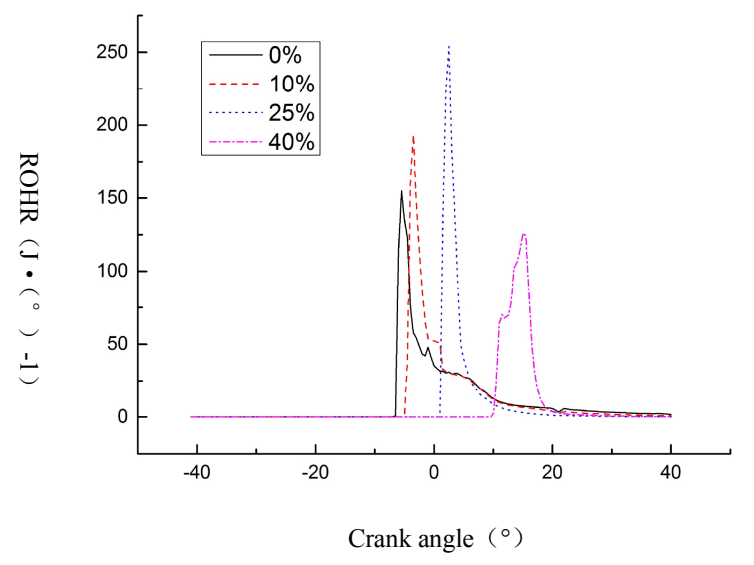

Fig. 5 ROHR Comparison of Different Water Content

When the moisture content of diesel is too high, Because of the evaporation of water, the temperature of the cylinder is lower,heat release rate become slower, reduce the internal combustion engine acting ability, the thermal efficiency as low moisture content of diesel, so there is the optimum blending ratio.

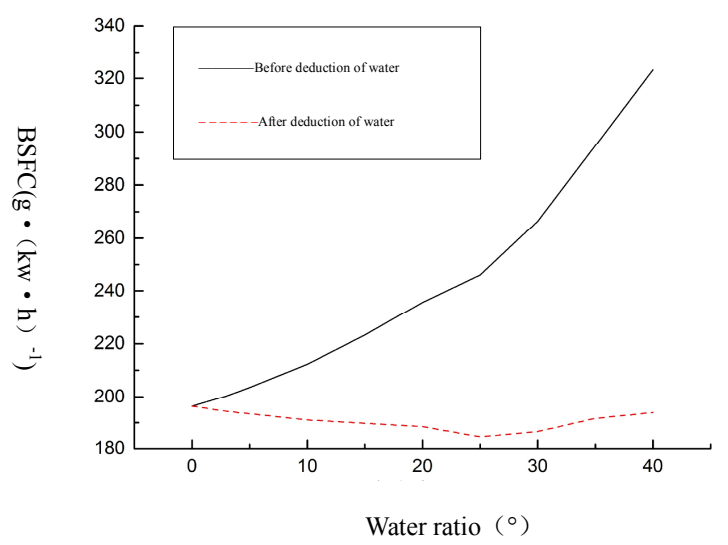

Fig. 6 Fuel Consumption Comparison of Different Water Content

Fig. 6 shows the different moisture content of the fuel consumption rate comparison, it can been seen that without considering the case of diesel the fuel consumption rate increases with the ratio of mixed water increasing.

Because of a certain amount of water in the emulsified diesel, the value of the emulsified diesel is lower than that of ordinary diesel. In the calculation of emulsified diesel fuel consumption to conduct numerical, converted to diesel fuel consumption, and then compare the fuel consumption and conversion formula as follows:

$b_{z} Q_{d}=\xi \mathrm{Wb}_{\mathrm{e}} \mathrm{Q}_{\mathrm{w}}+(1-\xi \mathrm{W}) \mathrm{b}_{\mathrm{e}} \mathrm{Q}_{\mathrm{d}}$

Because of the calorific value of water is 0 , that is, the $\mathrm{Q}$ water $=0$, then

$b_{z}=(1-\xi W) b_{e}$

Among: bz-The conversion of fuel consumption of emulsified diesel; 


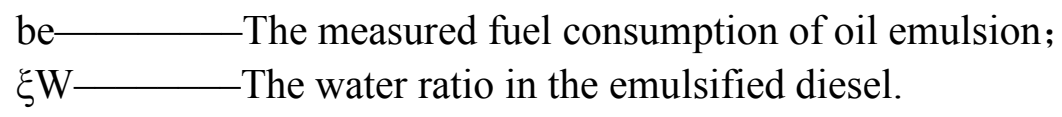

According to the calculation of the above formula (2), fuel consumption rate was shrinking trend, and when the moisture content is $25 \%$ under the condition of minimum fuel consumption, fuel consumption rate compared to neat fuel up to reduce by $6.06 \%$

The reson why emusified diesel can saving oil are shown as followings:1, water will reduce the cylinder average combustion temperature, thus reducing the heat loss through the cylinder wall.2, due to the evaporation of water, it could increase the $\mathrm{CO}+\mathrm{H}_{2} \mathrm{O} \rightarrow \mathrm{CO}_{2}+\mathrm{H}_{2}$ water gas reaction rate.3, in the environment of high temperature and oxygen conditions, diesel is easy to crack down on carbon and hydrogen. The precipitated carbon atoms react immediately with the $\mathrm{H} 2 \mathrm{O}$, that is called water gas reaction.

When the diesel watering amount is too large, the absorption process caused by evaporated water will make cylinder temperature too low so that affect the combustion process in the cylinder resulting in heat release decreases, the oil saving effect will be greatly weaken.

\section{Conclusion}

1.With the increasing of the proportion of water in emulsified diesel, the highest combustion pressure in the cylinder would constantly falling until can not be ignited. When the moisture content is $3 \%$, the maximum pressure of the cylinder increases slightly by $0.15 \%$

2.Ignition delay time is increasing, the heat release rate curve will be further to the TDC, increasing the cycle power and reducing the compression power, making the combustion process come to an end earlier.

3. Without consideration of the diesel blended with water, emulsified diesel consumption rate keep risig while the water ratio rising, but after deduction of the corresponding proportion of water, fuel consumption is a trend of shrinking. When the water content is $25 \%$, the fuel consumption is the lowest, the rate of fuel consumption compared to the neat fuel is reduced by $6.06 \%$ at most.

\section{References}

[1]Lou Di-ming, Bian Wei, Tan Pi-qiang.Experimental.Vehicle Engine.2010,(03):74-78. In Chinese

[2]Shi De-sheng,Xu Feng ,LONG Wu-qiang.Combustion.Chinese Internal Combustion Engine Engineering, 2006, 27(01):18-22.In Chinese

[3]Zeng Jian- mou,Chen Peng,Kong Jun- liang.Applied.Vehicle Engine, 2005, (4):64-66. ) In Chinese

[4]Han Da-ming,Wang Meng.Experiment on Dynamic.Journal Of North East Forestry University,2009,(02):103-104.) In Chinese

[5]Sun Ping,HU Jian-yue, Chen Zhen.Small Internal combustion Engine and Motorcycle.2010, (01):7-10. In Chinese

[6]Gong Jinsong, Fu Weibiao.Fuel,2001, 80:437-445.

[7]Yasufumi Yoshimoto, T.K.,Ziye Li, Minoru Tsukahara.Energy Fuels, 1998,Vol.26, No.1;2 $0-26$

[8]Li Yun-qing, Liu Bin, Wang Hui-xia.Design \& Manufacture of Diesel Engine, 2007,(0 3):6-9 In Chinese 
International Forum on Energy, Environment Science and Materials (IFEESM 2015)

[9]YANG Guang, YANG Zhen-zhong.Machinery Design \& Manufacture，2013，(04）:90-93. In Chinese 